\title{
Evaluation of the in vitro trypanocidal activity of methylated flavonoid constituents of Vitex simplicifolia leaves
}

Ngozi Nwodo ${ }^{1,3^{*}}$, Festus Okoye ${ }^{3,4}$, Daowan Lai ${ }^{3}$, Abdesammed Debbab ${ }^{3}$, Marcel Kaiser ${ }^{2,5}$, Reto Brun ${ }^{2,5}$ and Peter Proksch ${ }^{3}$

\begin{abstract}
Background: Trypanosomiasis is a neglected tropical disease with complex clinical manifestations, tedious diagnosis, and difficult treatments. The drugs available for the treatment of this endemic disease are old, expensive, and associated with other problems including safety and drug resistant parasites. Therefore, there is an urgent need for the development of new, effective, cheap, and safe drugs for its treatment. Plants are potentially rich sources of leads for new drugs against trypanosomiasis.

Vitex simplicifolia (Verbenaceae) is used traditionally for the treatment of tooth ache, edema, skin diseases, gout and trypanosomiasis in Nigeria. In a preliminary study, the methanol extract of Vitex simplicifolia was shown to exhibit a pronounced trypanocidal activity against T. b. rhodesiense.

The present study was undertaken to investigate the active component responsible for the acclaimed activity of the leaves of Vitex simplicifolia in the traditional treatment of trypanosomiasis in Nigeria and other African countries. Our investigations aim at assessing the plant as a new source of potential trypanocidal compounds.

Methods: The crude extracts were prepared from the dried leaves using methanol, successive extraction with hexane, dichloromethane, ethylacetate and butanol was also done. The ethylacetate fraction was further fractionated and compounds isolated using preparative chromatographic technique and their structures were elucidated by NMR, mass spectrometry and comparison with literature data. Trypanocidal activities and cytotoxicity, using rat skeletal myoblast (L6) cells were investigated and their selectivity indices were determined.
\end{abstract}

Results: The chromatographic separations of the methanol extracts gave rise to seven compounds. The isolated compounds 2, 3, 6 and 7 exhibited promising trypanocidal activity with $I_{50}$ values ranging from 4.7-12.3 $\mu \mathrm{g} / \mathrm{ml}$ and cytotoxicity in the range of $1.58-46.20 \mu \mathrm{g} / \mathrm{ml}$. Compound 6 , however, showed the most selective trypanocidal activity with a selectivity index of 9.8. This is the first report of trypanocidal activity of flavonoids from this plant genus.

Conclusions: The isolated compounds from Vitex simplicifolia exhibited noteworthy trypanocidal activities and hence may provide a source of new antitrypanosomal agents. These results also support the traditional use of Vitex simplicifolia in the treatment of trypanosomiasis. This is the first report of trypanocidal effect of flavonoids from this plant genus.

Keywords: Vitex simplicifolia, Verbenaceae, Flavonoids, Trypanosoma brucei rhodesiense

\footnotetext{
* Correspondence: nwodong@hotmail.com

${ }^{1}$ Department of Pharmaceutical and Medicinal Chemistry, University of

Nigeria, Nsukka, Nigeria

${ }^{3}$ Institute for Pharmaceutical Biology and Biotechnology,

Heinrich-Heine-University, D- 40225 Dusseldorf, Germany

Full list of author information is available at the end of the article
} 


\section{Background}

Human African trypanosomiasis also known as African sleeping sickness is caused by the protozoan parasites Trypanosoma brucei rhodesiense and Trypanosoma brucei gambiense in countries of sub-Saharan Africa [1]. World Health Organization (WHO) categorized it among the neglected tropical diseases which threatens primarily rural populations and is fatal unless treated. The use of the currently available drugs for the treatment of sleeping sickness has been limited owing to their numerous side effects, difficulty in administration and a certain loss of efficacy [2]. There is a great need for new safe chemotherapeutic agents preferably with oral application. In the drug pipeline managed by the Drugs for Neglected Diseases initiative (DNDi) two molecules are in clinical trial phases, fexinidazole and SCYX-7158 [3,4]. Drug discovery efforts are also directed towards natural products as an alternative source to synthetic compounds. Studies have revealed that many plant species are potential sources of novel trypanocidal compounds [5-9].

Vitex simplicifolia (Verbenaceae) is a sprawling shrub that can grow as tall as $1.5 \mathrm{~m}$ in height [10]. The leaves are strongly aromatic, intensifying when crushed and measure 2-6.5 cm in length and 1-4.5 cm in width [11]. The leaves and the edible fruits of $V$. simplicifolia are used in traditional medicine for the treatment of malaria, skin diseases, toothache, edema, gout and dermatitis [12]. In southern China, V. simplicifolia is used for the treatment of various pain disorders, such as stomach ache, hernia ache, dysmenorrhea, arthralgia, and piles [13]. Over the years, folk medicine has remained a veritable platform for researchers for sourcing lead compounds for the development of potent therapeutic agents. Several trypanocidal molecules have been isolated from plants with undefined side effects $[14,15]$. Flavonoids are one of the largest and most abundant classes of secondary metabolites in plants and mainly found in fruits and vegetables. Many flavonoids of plant origin have shown to possess a variety of medicinal properties [16-18]. Previous studies have demonstrated some structure activity relationships among flavonoid derivatives and their trypanocidal and /or antileishmanial activities [19-23]. So far, no similar flavonoids or its derivatives have been reported to possess trypanocidal activity against African trypanosomes. In this study, we report for the first time the trypanocidal activity of some methylated flavonoid derivatives from Vitex simplicifolia.

\section{Methods}

\section{General experimental procedures}

Optical rotations were determined on a Perkin-Elmer$241 \mathrm{MC}$ polarimeter. 1D and 2D NMR spectra were recorded on an Avance DMX 600 NMR spectrometer. Chemical shifts were referenced to the residual solvent peak at $\delta_{\mathrm{H}} 7.26\left(\mathrm{CDCl}_{3}\right)$ and 2.05 (acetone- $\left.d_{6}\right)$ for ${ }^{1} \mathrm{H}$, and $\delta_{\mathrm{C}} 77.0\left(\mathrm{CDCl}_{3}\right)$ and $29.92\left(\right.$ acetone- $\left.d_{6}\right)$ for ${ }^{13} \mathrm{C}$, respectively. Mass spectra were measured with a LCMS HP1100 Agilent Finnigan LCQ Deca XP Thermoquest and high-resolution electrospray ionization mass spectroscopy (HRESIMS) were recorded with an UHR-TOF maXis 4G (Bruker Daltonics, Bremen) mass spectrometer. HPLC analysis was performed with a Dionex P580 system coupled to a photodiode array detector (UVD340S); routine detection was at 235, 254, 280 , and $340 \mathrm{~nm}$. The separation column (125x $4 \mathrm{~mm}$ ) was prefilled with Eurosphere-10 C18 (Knauer, Germany), and the following gradient was used $\left(\mathrm{MeOH}, 0.1 \% \mathrm{HCOOH}\right.$ in $\left.\mathrm{H}_{2} \mathrm{O}\right): 0-5$ min $(10 \%$ $\mathrm{MeOH}) ; 5-35 \min (10-100 \% \mathrm{MeOH}) ; 35-45 \min$ $(100 \% \mathrm{MeOH})$.

Semi-preparative HPLC was performed using a Merck Hitachi HPLC System (UV detector L-7400; Pump L-7100; Eurosphere-100 C18, $300 \times 8$ mm, Knauer, Germany). Column chromatography was performed on Silica gel $60 \mathrm{M}$ (230-3400 mesh ASTM, Macherey-Nagel GmbH \& Co. KG, Dueren, Germany) and Sephadex LH-20 (Sigma). TLC was carried out on precoated silica gel plates (silica gel 60 F-254, Merck KGaA, Darmstadt, Germany) for monitoring of fractions. Detection was performed at 254 and $366 \mathrm{~nm}$.

\section{Plant material}

The leaves of Vitex simplicifolia were collected between March and April 2012 from Nsukka, Enugu State, Nigeria. The plant material was authenticated by Mr. Alfred Ozioko of the Centre for Ethnomedicine and Drugs Development, a subsidiary of Bioresources Development and Conservation Program (BCDP), Nsukka, Enugu State. The voucher specimens were deposited at the herbarium of the Department of Pharmacognosy, University of Nigeria, Nsukka. The leaves were cleaned, dried under room temperature and pulverized.

\section{Extraction and isolation procedures}

About $600 \mathrm{~g}$ of the powdered leaves of $V$. simplicifolia was extracted with 2.51 of methanol for 24 hours with constant stirring using a magnetic stirrer. The methanol extract $(45 \mathrm{~g})$ was dispersed in water and successively extracted with hexane, dichloromethane (DCM), ethylacetate and butanol. The chromatographic separations of the DCM fraction $(428.8 \mathrm{mg})$, using Vacuum Liquid Chromatography (VLC) $22 \times 4 \mathrm{~cm}$ on silica gel (230400 mesh) with gradient of $n$-hexane: ethylacetate led to 10 VLC fractions A-J. Fraction E (72.2 mg) eluted with $50 \%$ n-hexane: ethylacetate was subjected to semipreparative HPLC (Merck, Hitachi L-7100) using a Eurosphere $100-10 \mathrm{C} 18$ column $(300 \times 8 \mathrm{~mm}$, i.d.) with the following gradient (MeOH:H2O): 0 mins, $50 \%$ 
$\mathrm{MeOH} ; 0$ mins, 50\% $\mathrm{MeOH} ; 4$ mins, 60\% $\mathrm{MeOH} ; 5$ mins, 65\% $\mathrm{MeOH}$; 12 mins, 85\% $\mathrm{MeOH}$; 14 mins 90\% $\mathrm{MeOH}$; 15 mins, 100\% MeOH; 16 mins, $100 \% \mathrm{MeOH}$ to obtain compounds 1 (8.0 mg), 2 (5.8 mg), 3 (1.8 mg), 4 (1.9 mg), 5 (3.0 mg), 6 (1.8 mg) and 7 (2.0 mg).

\section{Determination of in vitro trypanocidal activity and cytotoxicity}

Minimum essential medium (50 $\mu \mathrm{l})$ supplemented according to a standard method [24], with 2-mercaptoethanol and $15 \%$ heat inactivated horse serum was added to each well of a 96-well microtiter plate. Serial three-fold compound dilutions were prepared covering a range from 90 to $0.123 \mu \mathrm{g} / \mathrm{ml}$. Then $10^{4}$ bloodstream forms of Trypanosoma brucei rhodesiense STIB 900 (a clone of a population isolated in 1982 from a patient in Tanzania) in $50 \mu \mathrm{l} \mathrm{cul-}$ ture medium were added to each well and the plate incubated at $37^{\circ} \mathrm{C}$ under a $5 \% \mathrm{CO}_{2}$ atmosphere for $72 \mathrm{~h}$. Ten microlitres of Alamar Blue (12.5 mg resazurin dissolved in $100 \mathrm{ml}$ distilled water) were then added to each well and incubation continued for a further $2-4 \mathrm{~h}$. The plate was then read in a Spectramax Gemini XS microplate fluorometer (Molecular Devices Cooperation, Sunnyvale, CA, USA) using an excitation wavelength of $536 \mathrm{~nm}$ and emission wavelength of $588 \mathrm{~nm}$ [25]. Fluorescence development was measured and expressed as percentage of the control. Data were transferred into the graphic programme Softmax Pro (Molecular Devices) which calculated $\mathrm{IC}_{50}$ values. Melarsoprol was used as standard drug.

Cytotoxicity was determined using a rat skeletal myoblast cell line (L6 cells). The culture medium was RPMI 1640 supplemented with L-glutamine $2 \mathrm{mM}$, HEPES $5.95 \mathrm{~g} / \mathrm{l}, \mathrm{NaHCO}_{3} 2 \mathrm{~g} / \mathrm{l}$ and $10 \%$ foetal bovine serum. Podophyllotoxin (Sigma-Aldrich) was used as the reference drug. The assay was performed following the antitrypanosomal assay protocol as described above. The $\mathrm{IC}_{50}$ values were calculated from the sigmoidal growth inhibition curves using Softmax Pro software (Molecular Devices Corp.). Tests were done in three independent experiments in duplicate.

\section{Results and discussion}

In a previous preliminary study, the methanol extract of Vitex simplicifolia was shown to exhibit a moderate trypanocidal activity against $T$. $b$. rhodesiense with an $\mathrm{IC}_{50}$ value of $14.2 \mu \mathrm{g} / \mathrm{ml}$ [26]. The methanol extract was therefore subjected to further fractionation and purification to identify the active components leading to the isolation of seven flavonoid derivatives (1-7).

The structures of the isolated flavonoid derivatives in Figure 1 were elucidated by a combination of $1 \mathrm{D}$ and $2 \mathrm{D}$ NMR and mass spectral analyses and comparison of the data with those reported in the literature as 2-(5' -methoxyphenyl)-3,4',5,7,8-trihydroxychroman-4-one (1), 2- (5'-methoxyphenyl) 4',5,7-trihydroxy-3-methoxychromen-4-one (2), Penduletin (3), 2-(4' -hydroxyphenyl)5-hydroxy 3,7- dimethoxy chromen-4-one (4), 2-(4hydroxyphenyl)-3,5,7-trihydroxy chromen-4-one (5), Artemetin (6) and 2-(3',4'-dimethoxyphenyl)-7hydroxychromen-4-one (7). All the seven compounds in Figure 1 were isolated from Vitex simplicifolia for the first time. Compounds $\mathbf{3}$ and $\mathbf{6}$ have been isolated from a related Vitex species Vitex trifolia, while the others were isolated from the genus Vitex for the first time.

All isolated compounds were subjected to in vitro assays assessing the trypanocidal and cytotoxic activities. The results are shown in Table 1.

Four of the isolated compounds 2, 3, 6 and 7 exhibited moderate trypanocidal activities with $\mathrm{IC}_{50}$ values ranging from 4.7-13.8 $\mu \mathrm{g} / \mathrm{ml}$, however, selectivity versus mammalian L6 cells was completely missing for 2, 3, and 7 . Compound 6 showed the most promising and selective trypanocidal activity $\left(\mathrm{IC}_{50}=4.7 \mu \mathrm{g} / \mathrm{ml}\right)$ with a selectivity index of 9.8. A close look at the structures of the isolated compounds reveals some structural features that can be correlated with the activities. The trypanocidal activity appears to increase with increase in the methylation of the hydroxyl groups. A plausible explanation for this observation is the corresponding increase in lipophilicity, which increases the permeability of the compounds across the parasite's membranes. This is in line with other investigations which stated that substitution at C4" especially with methoxyl group seems relevant for antiplasmodial activity [20]. Similar studies inferred that methylation at C-4" of the flavonols potentiates the trypanocidal activities [18]. Another report stated that association of methoxyl group at C-7 with hydroxyl group at C-4" is responsible for the trypanocidal activities of some flavonoids [27]. It might as well imply that hydroxyl at C-7 associates with the methoxyl group at C-4". In this study, it can be inferred that the presence of methoxyl group at $\mathrm{C}-3$, which is common to all the active compounds in this case, could be attributed to their activities. Furthermore, the absence of an $\mathrm{OH}$ group on the ring $\mathrm{B}$ which is the case with the most active compound could be another reason for its activity. According to a similar finding, the effect of the methoxyl groups on the flavonoid rings in relation to our findings needs further classifications [19].

\section{Conclusions}

In conclusion, the flavonoids isolated from $V$. simplicifolia showed low to moderate trypanocidal activity in vitro with compound $\mathbf{6}$ as the most active of the isolated molecules with a promising trypanocidal activity and some selectivity. A similar study shows compounds isolated from plants with $\mathrm{IC}_{50 \mathrm{~s}}$ from 1.6 to $19.4 \mu \mathrm{M}$ and 
<smiles>O=c1cc(-c2ccccc2)oc2cccc(O)c12</smiles>

Flavon-5-ol

$\begin{array}{lllccccc} & 3 & 6 & 7 & 8 & 3 & 4 & 5 \\ \mathbf{2} & \mathrm{OCH}_{3} & \mathrm{H} & \mathrm{OH} & \mathrm{H} & \mathrm{H} & \mathrm{OH} & \mathrm{OCH}_{3} \\ \mathbf{3} & \mathrm{OCH}_{3} & \mathrm{OCH}_{3} & \mathrm{OCH}_{3} & \mathrm{H} & \mathrm{H} & \mathrm{OH} & \mathrm{H} \\ \mathbf{4} & \mathrm{OCH}_{3} & \mathrm{H} & \mathrm{OCH}_{3} & \mathrm{H} & \mathrm{H} & \mathrm{OH} & \mathrm{H} \\ \mathbf{5} & \mathrm{OH} & \mathrm{H} & \mathrm{OH} & \mathrm{H} & \mathrm{H} & \mathrm{OH} & \mathrm{H} \\ \mathbf{6} & \mathrm{OCH}_{3} & \mathrm{OCH}_{3} & \mathrm{OCH}_{3} & \mathrm{H} & \mathrm{H} & \mathrm{OCH}_{3} & \mathrm{OCH}_{3}\end{array}$

1<smiles>COc1ccc(-c2oc3cc(O)ccc3c(=O)c2OC)cc1OC</smiles>

Figure 1 Chemical structures of the seven flavonoid derivatives isolated from Vitex simplicifolia (1-7).

Table 1 In vitro trypanocidal activity and cytotoxicity of flavonoids from Vitex simplicifolia against $T . b$ rhodesiense and $\mathbf{L} 6$ cells respectively

\begin{tabular}{|c|c|c|c|}
\hline Compound & $\begin{array}{l}\text { T.b.rhodesiense } \\
\mathrm{IC}_{50} \mu \mathrm{g} / \mathrm{ml}\end{array}$ & $\begin{array}{l}\text { L6 Cells } \\
\mathrm{IC}_{50} \mu \mathrm{g} / \mathrm{ml}\end{array}$ & SI \\
\hline 1 & 10.2 & 100 & 9.8 \\
\hline 2 & 12.3 & 6.64 & 0.5 \\
\hline 3 & 13.8 & 14.0 & 1.0 \\
\hline 4 & 19.4 & 28.2 & 1.4 \\
\hline 5 & 23.7 & 100 & 4.2 \\
\hline 6 & 4.7 & 46.2 & 9.8 \\
\hline 7 & 10.8 & 1.58 & 0.2 \\
\hline Melarsoprol & 0.002 & & \\
\hline Podophyllotoxin & & 0.005 & \\
\hline
\end{tabular}

SI: selectivity index (IC $\mathrm{I}_{50}$ of $\mathrm{L} 6$ cells/ $\mathrm{IC}_{50}$ of T.b.rhodesiense). selectivity indices between 0.5 and 6.5 [14]. To the best of our knowledge this is the first report on trypanocidal activity of this class of compounds from this plant genus. Future optimization of these compounds through structural alteration may lead to molecules with improved trypanocidal activity and selectivity.

\section{Competing interests}

The authors declare that they have no competing interests.

\section{Authors' contributions}

NJN isolated, identified and prepared the manuscript; FBC contributed in the interpretation of the spectra and also in the proofreading of the manuscript. $\mathrm{DL}$ elucidated the structures of the compounds. $\mathrm{AD}$ is part of the grant that supported this work. PP made available the laboratory, including equipments, consumables and supervised isolation of these compounds. RB was responsible for the bioassays and contributed in the writing of the manuscript. All authors read and approved the final manuscript.

\section{Acknowledgements}

The Authors wish to acknowledge the grant from the Federal Ministry of Education and Research (BMBF), Germany, awarded to PP and AD which helped in actualizing this work. 


\section{Author details}

'Department of Pharmaceutical and Medicinal Chemistry, University of Nigeria, Nsukka, Nigeria. ${ }^{2}$ Department of Medical Parasitology and Infection Biology, Swiss Tropical and Public Health Institute, CH-4002 Basel, Switzerland. ${ }^{3}$ Institute for Pharmaceutical Biology and Biotechnology, Heinrich-Heine-University, D- 40225 Dusseldorf, Germany. ${ }^{4}$ Department of Pharmaceutical Chemistry, Nnamdi Azikiwe University, Awka, Anambra State, Nigeria. ${ }^{5}$ University of Basel, $\mathrm{CH}-4003$ Basel, Switzerland.

Received: 31 July 2014 Accepted: 18 February 2015

Published online: 26 March 2015

\section{References}

1. Brun R, Blum J, Chappuis F, Burri C. Human African trypanosomiasis. Lancet. 2010;375(9709):148-59.

2. Burri C, Chappuis F, Brun R. Human African trypanosomiasis. In: Farrar J, Hotez PJ, Junghans T, Kang G, Lalloo D, White N, editors. Manson's tropical diseases. 23rd ed. Edinburgh: Saunders/Elsevier; 2014. p. 606-21.

3. Brun R, Don R, Jacobs RT, Wang MZ, Barrett MP. Development of novel drugs for human African trypanosomiasis. Future Microbiol. 2011;6:677-91.

4. Drugs for Neglected Diseases initiative. DNDi R\&D Projects - 2013 Outlook http://www.dndi.org/diseases-projects/portfolio.html (accessed 22 May 2014)

5. Jones AJ, Grkovic T, Sykes ML, Avery VM. Trypanocidal activity of marine natural products. Marine Drugs. 2013;11(10):4058-82. doi: 10 3390/md11104058.

6. Asuzu IU, Chineme CN. Effects of Morinda lucida leaf extract on Trypanosoma brucei brucei infection in mice. J Ethnopharm. 1990;30:307-13.

7. Nwodo NJ, Brun R, Osadebe PO. In vitro and in vivo evaluation of antitrypanosomal activity of fractions of Holarrhena africana. J Ethnopharmacol. 2007;113:556-9.

8. Ngure RM, Ongeri B, Karori SM, Wachira W, Maathai RG, Kabugu JK, et al. Anti-trypanosomal effects of Azadirachta indica (neem) extract on Trypanosoma brucei rhodesiense infected mice. Eastern J Med. 2009;14:2-9.

9. Nwodo NJ, Agbo MO. Antitrypanosomal effects of methanolic extracts of Nauclea diderrichii (Merr) and Spathodea campanulata stem bark. J Pharm Allied Sci. 2010;7(5):1219-27.

10. Munir AA. A taxonomic revision of the genus Vitex $L$ (Verbenaceae) in Australia. J Alelaide Botanic Garden. 1987;10(1):31-79.

11. Keay RWJ: The trees of Nigeria. 1964, 20:340-345.

12. Liang F, Zhou X, Cao L. Investigation report on Vitex trifolia L.var. Simplicifolia cham. Medicinal plant resources in china. Medicinal Plant. 2012;3(1):16-9. 22.

13. Zhoug S, QIU GD, LIU YB, et al. Pharmacological activity comparism of Vitex trifolia $L$ var simplicifolia cham, Fructus viticis, Vitex negundo chastetree fruit. Pharmacol Clin Chinese Materia Medica. 1996;12(1):37.

14. Julianti T, Yoshie $Y$, Zimmermann S, Kaiser M, Hamburger M, Adams M. Antitrypanosomal sesquiterpene lactones from Saussurea costus. Fitoterapia. 2011:82:955-9.

15. Herrmann F, Sporer F, Tahrani A, Wink M. Antitrypanosomal properties of Panax ginseng C. A. Meyer: New possibilities for a remarkable traditional drug. Phytother Res. 2013;27:86-98.

16. Tim Cushnie TP, Lamb AJ. Review antimicrobial activity of flavonoids. Int J Antimicrobial Agents. 2005;26(5):343-56.

17. Joe ES, Eunjung L, Sang GS, Jihoon L, Jong EK, Jiyoung K, et al. Eupatilin, a major flavonoid of artemisia, attenuates aortic smooth muscle cell proliferation and migration by inhibiting PI3K, MKK3/6, and MKK4 activities. Planta Med. 2013;79:1009-16.

18. Taleb-Contini SH, Salvador MJ, Balanco JMF, Albuquerque S, de Oliveira DCR. Antiprotozoal effect of crude extracts and flavonoids isolated from Chromolaena hirsuta (asteraceae). Phytotherapy Res. 2004;18(3):250-4.

19. Tasdemir D, Kaiser M, Brun R, Yardley V, Schmidt TJ, Tosun F, et al. Antitrypanosomal and antileishmanial activities of flavonoids and their analogues: In vitro, In vivo, structure-activity relationship, and quantitative structure-activity relationship studies. Antimicrob Agents Chemother. 2006:50(4):1352-64.

20. Weniger B, Vonthron-Se'ne'cheau C, Kaiser M, Brun R, Anton R. Comparative antiplasmodial, leishmanicidal and antitrypanosomal activities of several biflavonoids. Phytomedicine. 2006;13:176-80.

21. Jorda o CO, Vichnewski W, de Souza GE P, Albuquerque S, Lopes JLC. Trypanocidal activity of chemical constituents of Lychnophora salicifolia Mart. Phytother Res. 2004;18:332-4.
22. Yoshioka T, Inokuchi T, Fujioka S, Kimura Y. Phenolic compounds and flavonoids as plant growth regulators from fruit and leaf of Vitex rotundifolia. J Pharm Pharmcol. 2007:59:1307-12.

23. Keun MY, Kun HS, Hyeun WC, Sam SK, Hyun PK. Vitexicarpin, a flavonoid from the fruits of Vitex rotundifolia, inhibits mouse lymphocyte proliferation and growth of cell lines In vitro. Planta Med. 1998;64:546-50.

24. Baltz T, Baltz D, Giroud C, Crockett J. Cultivation in a semi-defined medium of animal infective forms of Trypanosoma brucei, T. equiperdum, T. evansi, T. rhodesiense and T. gambiense. EMBO J. 1985;4:1273-7.

25. Räz B, Iten M, Grether-Bühler $Y$, Kaminsky R, Brun R. The Alamar blue ${ }^{\oplus}$ assay to determine drug sensitivity of African trypanosomes (T. b. Rhodesiense and T.b. Gambiense) in vitro. Acta Trop. 1997;68:139-47.

26. Nwodo NJ, Agbo MO, Brun R. In vitro and In vivo antitrypanosomal studies of the leaf extract of Vitex simplicifolia. Afri J Pharma Res Dev. 2012;4(1):35-40.

27. Grecco SS, Reimão JQ, Tempone AG, Sartorelli P, Rodrigo LOR, Cunha ROR, et al. In vitro antileishmanial and antitrypanosomal activities of flavanones from Baccharis retusa DC. (Asteraceae). Exp Parasitol. 2012;130:141-5.

\section{Submit your next manuscript to BioMed Central and take full advantage of:}

- Convenient online submission

- Thorough peer review

- No space constraints or color figure charges

- Immediate publication on acceptance

- Inclusion in PubMed, CAS, Scopus and Google Scholar

- Research which is freely available for redistribution 